Original Research Article

\title{
Efficacy of risperidone and haloperidol in treatment of schizophrenia in tertiary care hospital
}

\author{
Lavanya Nagaraj $^{1}$, Naveen Kumar Madalageri ${ }^{2}$ *
}

${ }^{1}$ Department of Pharmacology, Sree Narayana Institute of Medical Science, Chalakka, Ernakulam, Kerala, India ${ }^{2}$ Department of Pharmacology, Al Azhar Medical College and Super speciality hospital, Ezhalloor, Thodupuzha, Kerala, India

Received: 25 September 2019

Revised: 10 October 2019

Accepted: 12 October 2019

*Correspondence to:

Dr. Naveen Kumar Madalageri, Email: dr.naveen.madalageri@ gmail.com

Copyright: (C) the author(s), publisher and licensee Medip Academy. This is an openaccess article distributed under the terms of the Creative Commons Attribution NonCommercial License, which permits unrestricted noncommercial use, distribution, and reproduction in any medium, provided the original work is properly cited.

\begin{abstract}
Background: Schizophrenia is a chronic debilitating disease with significant morbidity and mortality that often requires either typical or atypical antipsychotic pharmacotherapy. Atypical antipsychotic drugs are preferred over typical because of lower risk of extra pyramidal side effects. As there is paucity of data in Indian population, the present study was taken up to evaluate the efficacy of haloperidol and risperidone in the treatment of schizophrenia.

Methods: It was a comparative study conducted on 60 patients of Schizophrenia for one year in a tertiary care hospital. The study subjects were randomly assigned into 2 groups of 30 patients each, where group 1 were treated with atypical antipsychotic drug risperidone and group 2 with typical antipsychotic drug Haloperidol and both groups received the treatment for one year. Efficacy was measured using positive and negative syndrome scale (PANSS), clinical global impression - severity of illness (CGI-S), clinical global impression - improvement (CGI-I) scales.

Results: Both haloperidol and risperidone were associated with comparable baseline to endpoint reduction in symptom severity. However, risperidone treated subjects had significantly greater decrease in symptom severity as measured by PANSS score and total score, CGI-S scale. However, there is no significant difference between two groups in terms of CGI-S score.

Conclusions: The reduction in positive, negative and general scores in risperidone treated patients were significant with that of haloperidol treated patients.
\end{abstract}

Keywords: Risperidone, Haloperidol, Efficacy, Typical antipsychotics, Atypical antipsychotics

\section{INTRODUCTION}

Schizophrenia is one of the chronic psychotic disorder characterised by characterized by delusions, hallucinations, incoherence and physical agitation. ${ }^{1}$ It is one of the leading causes of disability in India with prevalence of $2.3 / 1000$ population.

It is characterised by positive symptoms like delusions, hallucinations, grossly disorganised thought, agitation and negative symptoms include alogia, flattened affect, anhedonia and avolition. ${ }^{2}$
There are several neurotransmitters like dopamine (D), serotonin (5HT), acetylcholine (Ach) and glutamate imbalances are being implicated in its pathophysiology. ${ }^{2}$ Disease course is variable and mostly chronic, characterized by on-going functional impairment and the frequent recurrence of acute psychotic symptoms. ${ }^{3}$

It is a chronic debilitating disease with significant morbidity and mortality that often requires antipsychotic pharmacotherapy for life. The treatment of schizophrenia remains an enormous challenge. Typical antipsychotic medications like haloperidol, chlorpromazine and trifluoperazine are shown to suppress the acute psychotic 
symptoms of schizophrenia and prevent their recurrence. However, many patients suffer from side effects like extra pyramidal signs and tardive dyskinesia. More over typical antipsychotics have limited efficacy in resistant cases. ${ }^{4}$

Atypical antipsychotics like risperidone, olanzapine and clozapine have better efficacy and less side effects in comparison with typical antipsychotics. They are also better tolerated and better efficacious in treating resistant cases. $^{4,5}$

Studies comparing typical and atypical antipsychotic drug showed equal efficacy or, at most modest therapeutic superiority for the atypical drug in positive, negative, cognitive and mood symptoms, have lower risk of extra pyramidal adverse effects, which improves patient compliance. ${ }^{5,6}$

As there is paucity of data in Indian population the present study has been taken up to evaluate the efficacy of risperidone (atypical) and haloperidol (typical) antipsychotic drugs in the treatment of schizophrenic patients in a tertiary care hospital.

\section{METHODS}

Patient data was collected from outpatients and inpatients in the department of psychiatry, Victoria hospital, Bangalore. It was a prospective observational study conducted from January 2010 to June 2011. After obtaining approval and clearance from the institution ethical committee, 60 patients with schizophrenia who gave written informed consent were included for the study. The study subjects fulfilling the inclusion or exclusion criteria were randomly assigned into 2 groups of 30 patients in each group. Group 1 was considered as patients treated with risperidone (oral dose 0.25 to $4 \mathrm{mg}$ ) and Group 2 was patients treated with haloperidol (oral doses $1 \mathrm{mg}$ to $10 \mathrm{mg}$ ).

\section{Inclusion criteria}

Inclusion criteria were patients of either sex aged between 18-65 years suffering from schizophrenia; patients who fulfilled the criteria of ICD-10 (International Classification of Disease-10, WHO1992); patients in the respective groups who were on treatment with that particular drug for a minimum duration of 3 months; patients who gave written informed consent.

\section{Exclusion criteria}

Exclusion criteria were patients who received more than one antipsychotic medication and who had received them in the past one year; patient with major psychiatric illness; patients with co-morbid medical conditions like diabetes mellitus, dyslipidaemia, coronary heart disease, hypertension, Parkinson disease, patient with concomitant physical illness, presence of alcohol and substance abuse/dependence, epilepsy, mental retardation, mental disorders other than schizophrenia, patient suffering from any major endocrine disorders, pregnant and lactating women, non-compliant patients who were unable to give consent for the study.

Efficacy was assessed by positive and negative syndrome scale (PANSS), clinical global impression- severity of illness (CGI-S) and clinical global impression- global improvement (CGI-I) scale. ${ }^{7,8}$

In first visit i.e. day one, patients were informed fully about the purpose and requirements of the study and written informed consent has been obtained. Details of patient's medical history, concomitant medication, pill count and detailed physical/psychiatric evaluation were recorded. Blood samples for relevant baseline laboratory investigations were collected. Concomitant use of anticholinergics, selective serotonin reuptake inhibitors, benzodiazepines and electroconvulsive therapy are permitted as and when needed. Patients were issued medication once every month and instructed for regular follow up there after. Patients were clinically assessed once in 3 months and relevant laboratory during subsequent visits i.e. visit $2\left(3^{\text {rd }}\right.$ month), visit $3\left(6^{\text {th }}\right.$ month), visit 4 ( $9^{\text {th }}$ month) and visit 5 (1 year) medication compliance, pill count, any intercurrent illness or change in concomitant medications were recorded. A thorough physical/ psychiatric evaluation was carried out and recorded.

\section{Statistical methods}

Descriptive statistical analysis has been carried out in the present study. Results on continuous measurements are presented on Mean \pm SD (Min-Max) and results on categorical measurements are presented in number $(\%)$. Significance is assessed at $5 \%$ level of significance.

It was assumed that dependent variables were normally distributed. It was also assumed that samples drawn from the population were random, and cases of the samples were independent. Chi-square/ Fisher exact test has been used to find the significance of study parameters on categorical scale between two groups.

\section{RESULTS}

In the present study, there is reduction in mean positive score at every visit compared to baseline scores. But there is significant difference in the mean positive score of visit-5 (at the end of one year) compared to baseline $(\mathrm{p}<0.001)$. There was statistically significant reduction in positive score among both groups.

As shown in Table 1, there was reduction in mean negative score at every visit compared to baseline scores. But there was significant difference in the mean negative score of visit- 5 compared to baseline $(p<0.001)$. There was statistically significant reduction in negative score among both groups. 
There was reduction in mean general score at every visit compared to baseline scores. But there is significant difference in the mean general score of visit-5 compared to baseline $(\mathrm{p}<0.001)$. There was statistically significant reduction in general score among both groups. Group II showed strongly significant reduction in general score with $\mathrm{p}<0.001$ in comparison to group I.
There was reduction in mean total score at every visit compared to baseline scores. But there is significant difference in the mean total score of visit-5 compared to baseline $(\mathrm{p}<0.001)$. Both the groups showed statistically significantly reduction in the positive score.

Table 1: Psychiatric evaluation of study subjects by positive and negative symptom score.

\begin{tabular}{|c|c|c|c|c|}
\hline Psychiatric evaluation & $\begin{array}{l}\text { Group I } \\
\text { (risperidone) }\end{array}$ & $\begin{array}{l}\text { Group II } \\
\text { (haloperidol) }\end{array}$ & P value & $\begin{array}{l}\text { Group wise comparison } \\
\text { I-II }\end{array}$ \\
\hline \multicolumn{5}{|l|}{ Positive score } \\
\hline Visit 1 & $30.07 \pm 5.88$ & $33.73 \pm 5.33$ & $0.063+$ & $0.050 *$ \\
\hline Visit 2 & $26.03 \pm 5.08$ & $27.70 \pm 5.33$ & 0.360 & 0.467 \\
\hline Visit 3 & $22.33 \pm 4.61$ & $22.13 \pm 4.37$ & 0.259 & 0.986 \\
\hline Visit 4 & $19.30 \pm 4.52$ & $17.80 \pm 4.01$ & $0.007 * *$ & 0.416 \\
\hline Visit 5 & $16.40 \pm 4.31$ & $13.73 \pm 3.83$ & $<0.001 * *$ & $0.056+$ \\
\hline \multicolumn{5}{|l|}{ Negative score } \\
\hline Visit 1 & $30.80 \pm 5.89$ & $33.23 \pm 5.12$ & 0.225 & 0.241 \\
\hline Visit 2 & $26.60 \pm 4.95$ & $27.47 \pm 4.83$ & 0.488 & 0.785 \\
\hline Visit 3 & $22.20 \pm 4.26$ & $21.87 \pm 4.75$ & 0.512 & 0.958 \\
\hline Visit 4 & $19.40 \pm 4.21$ & $17.43 \pm 3.98$ & $0.003 * *$ & 0.372 \\
\hline Visit 5 & $17.40 \pm 5.25$ & $13.27 \pm 3.82$ & $<0.001 * *$ & $0.004 * *$ \\
\hline \multicolumn{5}{|l|}{ General score } \\
\hline Visit 1 & $57.67 \pm 15.08$ & $62.00 \pm 17.78$ & 0.455 & 0.599 \\
\hline Visit 2 & $49.90 \pm 13.32$ & $52.20 \pm 16.95$ & 0.617 & 0.841 \\
\hline Visit 3 & $41.63 \pm 11.87$ & $41.47 \pm 14.19$ & 0.583 & 0.999 \\
\hline Visit 4 & $38.00 \pm 11.66$ & $33.57 \pm 12.04$ & $0.021 *$ & 0.361 \\
\hline Visit 5 & $33.83 \pm 12.09$ & $26.10 \pm 8.00$ & $<0.001 * *$ & $0.041 *$ \\
\hline \multicolumn{5}{|l|}{ Total score } \\
\hline Visit 1 & $118.53 \pm 25.99$ & $129.87 \pm 26.55$ & 0.253 & 0.260 \\
\hline Visit 2 & $102.53 \pm 22.43$ & $106.13 \pm 26.72$ & 0.578 & 0.848 \\
\hline Visit 3 & $86.17 \pm 19.34$ & $85.47 \pm 21.55$ & 0.438 & 0.991 \\
\hline Visit 4 & $76.70 \pm 19.34$ & $68.80 \pm 18.17$ & $0.004 * *$ & 0.305 \\
\hline Visit 5 & $67.60 \pm 20.92$ & $53.10 \pm 13.74$ & $<0.001 * *$ & $0.019 *$ \\
\hline
\end{tabular}

$* \mathrm{p}<0.01, * * \mathrm{p}<0.001$.

Table 2: Psychiatric evaluation of study subjects by clinical global impression scale.

\begin{tabular}{|lllll|}
\hline Psychiatric evaluation & $\begin{array}{l}\text { Group I } \\
\text { (risperidone) }\end{array}$ & $\begin{array}{l}\text { Group II } \\
\text { (haloperidol) }\end{array}$ & P value & $\begin{array}{l}\text { Group wise comparison } \\
\text { I-II }\end{array}$ \\
\hline CGI-S & & & & \\
\hline Visit 1 & $2.57 \pm 0.57$ & $2.90 \pm 0.31$ & $0.002 * *$ & $0.007 * *$ \\
\hline Visit 2 & $2.20 \pm 0.41$ & $2.27 \pm 0.45$ & $0.014 *$ & 0.839 \\
\hline Visit 3 & $2.07 \pm 0.25$ & $1.87 \pm 0.51$ & $0.001 * *$ & 0.167 \\
\hline Visit 4 & $1.90 \pm 0.40$ & $1.40 \pm 0.49$ & $<0.001 * *$ & $<0.001 * *$ \\
\hline Visit 5 & $1.63 \pm 0.49$ & $1.20 \pm 0.41$ & $<0.001 * *$ & $0.001 * *$ \\
\hline CGI-I & & & 0.372 & 0.442 \\
\hline Visit 1 & $2.03 \pm 0.18$ & $2.00 \pm 0.00$ & 0.551 & 0.848 \\
\hline Visit 2 & $1.97 \pm 0.32$ & $1.93 \pm 0.25$ & $0.031 *$ & 0.133 \\
\hline Visit 3 & $1.83 \pm 0.38$ & $1.63 \pm 0.49$ & 0.278 & 0.446 \\
\hline Visit 4 & $1.27 \pm 0.45$ & $1.13 \pm 0.35$ & 0.132 & 0.188 \\
\hline Visit 5 & $1.07 \pm 0.25$ & $1.00 \pm 0.00$ & & \\
\hline
\end{tabular}

$* \mathrm{p}<0.01, * * \mathrm{p}<0.001$. 
As shown in Table 2, there was reduction in mean CGI-S score at every visit compared to baseline scores. But there is significant difference in the mean CGI-S score of visit5 (at the end of one year) compared to baseline $(\mathrm{p}<0.001)$. There was statistically significant reduction CGI-S in score among both groups.

There was mean reduction in CGI-I score at every visit compared to baseline scores. But the reduction in CGI-I score was not statistically significant in both groups.

\section{DISCUSSION}

The present observational comparative study on efficacy of haloperidol and risperidone in the treatment of schizophrenia was conducted in Department of Psychiatry, Victoria hospital over a period of 1 year 6 months. The present study included a total of 60 patients.

The schizophrenia may present with two distinct types of symptoms; positive and negative symptoms. Positive symptom includes delusions, hallucinations and disorganized thinking. Negative symptoms are characterized by deficits in cognitive, affective, and social functions, including blunting of affect and passive withdrawal. General Psychopathology is composed of many deficits in cognition such as disorientation, poor attention, lack of insight and active social avoidance. ${ }^{9}$

Psychiatric evaluation of study subjects by positive and negative symptom score. Positive symptoms of schizophrenia are due to dopaminergic D2 over activity in meso-limbic region. ${ }^{10}$ Negative symptoms are due to dopaminergic D2 over activity in mesocortical region, over activity of D4 dopamine receptor, abnormal frontal lobe circuit and abnormal serotonin transporter gene. ${ }^{11}$

In the present study there was mean decrease in positive symptom score from baseline to end of the study and there was statistically significant reduction in positive score among both groups. Tollefson et al showed that Olanzapine, risperidone and haloperidol significantly reduce the positive score without inter group variation. ${ }^{12}$ Contrarily; Volavka et al reported that atypical antipsychotics like clozapine, risperidone, and olanzapine resulted in statistically significant improvements in positive score compared to typical antipsychotics like haloperidol. $^{10}$

Negative symptoms impose great suffering on patients by impeding their rehabilitation and psychological functioning. Conventional D2 blocking agents lack therapeutic efficacy for negative symptoms and thus may explain their limitation in mediating the chronic course of schizophrenia. Atypical antipsychotics are more effective in reducing negative symptoms compared to typical antipsychotic drugs because of their selective D2 blocking action in mesolimbic and meso-cortical dopaminergic pathway. $^{10,11}$
In our study there was reduction in negative score among both groups. This was comparable to studies done by Volavka et al, found that improvements were seen in negative symptom scores with clozapine and olanzapine and risperidone were superior to haloperidol. ${ }^{10}$ Oliveira et al showed that greater reduction in negative score with risperidone compared to haloperidol. ${ }^{11}$

In our study there was statistically significant reduction in general score among both groups. Similar studies by Volavka et al found that reduction in general symptom scores with clozapine and olanzapine and risperidone were superior to haloperidol. ${ }^{10}$

There was statistically significant reduction in total score among both groups. Volavka et al found that Improvements seen in total score with clozapine and olanzapine and risperidone were superior to haloperidol. ${ }^{10}$

The clinical global impression rating scales are commonly used measures of symptom severity, treatment response and the efficacy of treatment. The CGI-S is a 7-point scale that requires the clinician to rate the severity of the patient's illness at the time of assessment. The CGI-I is a 7-point scale, is used to assess how much the patient's illness has improved or worsened relative to a baseline state at the beginning of the intervention. ${ }^{8}$ In our study there was statistically significant reduction in CGI-S score in both groups. Volavka et al, reported that improvements seen in CGI-S score with clozapine, olanzapine and risperidone were superior to haloperidol. ${ }^{10}$

In our study there was significant reduction in mean positive, negative and general symptoms as compared to baseline. In comparison with haloperidol, significant reduction of these symptoms was seen in patients who received risperidone. There was significant reduction of CGI-I and CGI-S score at every visit compared to baseline scores, but CGI-I score was not statistically significant in both groups.

There are some limitations of the study as number of patients in each group is less which necessitates more extensive study taking large number of patients.

\section{CONCLUSION}

The reduction in positive, negative and general scores in risperidone treated patients were significant with that of haloperidol treated patients. Risperidone was more efficacious than haloperidol in the treatment of schizophrenia.

\section{ACKNOWLEDGEMENTS}

We are thankful to Dr. C.R. Jayanthi (professor and head, department of pharmacology, BMCRI), Dr. H. Chandrashekar (professor and head, department of psychiatry, Victoria hospital, Bangalore) for their kind support thought the study. We are also thankful to Dr. 
Rekha, Dr Manjula, for their continuous cooperation during present study.

Funding: No funding sources

Conflict of interest: None declared

Ethical approval: The study was approved by the Institutional Ethics Committee

\section{REFERENCES}

1. Gelder MG, Lopez-Ibor. JJ, Andreasen N, editors. New Oxford Textbook of Psychiatry. Volume 1, 2ed. New York: Oxford University Press; 2000: 567-636.

2. Gosh A, Chakraborty K, Mattoo SK. Newer molecule in the treatment of schizophrenia: A clinical update. Indian J Pharmacol. 2011;43(2):105-12.

3. Sadock BJ, Sadock VA. Kaplan and Sadock's Comprehensive textbook of psychiatry, 7th ed. USA: Lippincott Williams and Wilkins; 2000:89.

4. Lieberman AJ, Tollefson G, Tolen M, Dr. P.H, Green AI, Gur RE, et al, Comparative efficacy and safety of atypical antipsychotic drugs in first-episode psychosis: A randomized, double blind trial of olanzapine versus haloperidol. Am J Psychiatr. 2003;160:1396-404.

5. Bruton LL, Lazo JS, Parker KL, editors. Goodman and Gillman's The Pharmacological Basis of Therapeutics. 10th ed. New York: McGraw hill; 2001: 485-507.

6. Kannabiran M, Singh V. Metabolic syndrome and atypical antipsychotic: A selective literature review. German J Psychiatr. 2008;11:111-22.

7. Kay SR, Fiszbein A, Opler LA The positive and negative syndrome scale (PANSS) for schizophrenia. Schizophr Bull. 1987;13(2):261-76.
8. Busner J, Targum SD. The clinical global impressions scale: applying a research tool in clinical practice. Psychiatry (Edgmont). 2007;4(7):28-37.

9. Sarkhel S. Kaplan and Sadock's Synopsis of Psychiatry: Behavioral Sciences/ Clinical Psychiatry, 10th edition. Indian J Psychiatr. 2009;51(4):331.

10. Volavka J, Czobor P, Sheitman B, Lindenmayer JP, Citrome L, McEvoy JP. Clozapine, olanzapine, risperidone, and haloperidol in the treatment of patients with chronic schizophrenia and schizoaffective disorder. Am J Psychiatry. 2002;159(2):255-62.

11. Lindenmayer JP, Khan A, Iskander A, Abad MT, Parker B. A Randomized Controlled Trial of Olanzapine versus Haloperidol in the Treatment of Primary Negative Symptoms and Neurocognitive Deficits in Schizophrenia. J Clin Psychiatr. 2007;68:368-79.

12. Tollefson GD, Beasley CM Jr, Tran PV, Street JS, Krueger JA, Tamura RN, et al. Olanzapine versus Haloperidol in the Treatment of Schizophrenia and Schizoaffective and Schizophreniform Disorders: Results of an International Collaborative Trial. Am J Psychiatr. 1997;154:457-46.

Cite this article as: Nagaraj L, Madalageri NK. Efficacy of risperidone and haloperidol in treatment of schizophrenia in tertiary care hospital. Int J Basic Clin Pharmacol 2019;8:2403-7. 